\title{
BMJ Open Proliferation of gynaecological scientific societies and their financial transparency: an Italian survey
}

\author{
Paolo Vercellini, ${ }^{1,2}$ Paola Viganò, ${ }^{2,3}$ Maria Pina Frattaruolo,, ${ }^{1,2}$ \\ Edgardo Somigliana ${ }^{2,4}$
}

To cite: Vercellini $P$, Viganò P, Frattaruolo MP, et al. Proliferation of gynaecological scientific societies and their financial transparency: an Italian survey. BMJ Open 2016;6: e008370. doi:10.1136/ bmjopen-2015-008370

- Prepublication history and additional material is available. To view please visit the journal (http://dx.doi.org/ 10.1136/bmjopen-2015008370).

Received 31 March 2015 Revised 20 November 2015 Accepted 24 November 2015

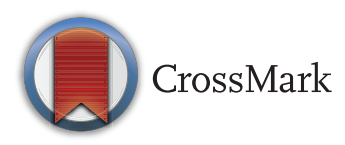

\footnotetext{
${ }^{1}$ Department of Clinical Science and Community Health, Università degli Studi di Milano, Milan, Italy ${ }^{2}$ Center for Research in Obstetrics and Gynaecology, Milan, Italy

${ }^{3}$ Department of Obstetrics and Gynaecology, Istituto Scientifico San Raffaele, Milan, Italy

${ }^{4}$ Infertility Unit, Fondazione IRCCS Ca' Granda-Ospedale Maggiore Policlinico, Milan, Italy
}

Correspondence to Professor Paolo Vercellini; paolo.vercellini@unimi.it

\section{ABSTRACT}

Objectives: To determine the number of Italian obstetrical and gynaecological societies, and to ascertain their financial transparency.

Design: Internet-based national survey and website content analysis.

Participants: Currently active, not privately owned, non-religious, apolitical, obstetrical and gynaecological associations.

Methods: From October 2014 to June 2015, scientific societies were identified using combinations of search terms, and examining the website of the two main Italian obstetrical and gynaecological organisations. Individual societies' websites were scrutinised by two independent investigators.

\section{Primary and secondary outcome measures:}

Number of Italian obstetrical and gynaecological associations and its variation over time; 12 information categories defining the general characteristics of the societies and their websites, and the financial transparency of the associations.

Results: The initial web search yielded 56 professional obstetrical and gynaecological associations but nine were excluded for various reasons. Of the remaining 47 professional associations, 17 covered both obstetrics and gynaecology, four were specialised in obstetrics, 26 in gynaecology and 46 provided continuing medical education (CME) activities. The number of societies has quadrupled in the last 35 years, increasing at a mean rate of one additional society per year. The headquarters of the associations were located in the offices of a professional congress organiser in 15 instances, and advertisements or links to industry products were present in 12 societies' websites. Bylaws were accessible in 32 websites. No information was publicly available regarding competing interests, financial statements and quantitative external funding.

Conclusions: The number of obstetrical and gynaecological societies is remarkably high in Italy, particularly in the gynaecological area. Despite CME activity provision, transparency of societies regarding financial issues and competing interests was almost non-existent. Policies addressing the interactions between medical associations and industry are available and should be implemented.

\section{Strengths and limitations of this study}

- Different search strategies were adopted to identify all currently active Italian obstetrical and gynaecological scientific societies, that is, Internet, interviewing executive personnel of the two main national organisations, and direct contact with some presidents and past-presidents.

- Two independent investigators retrieved information, abstracted data on standardised forms and conducted a website content analysis on 12 items regarding the general characteristics of the medical associations and their websites, as well as societies' financial transparency.

- The data presented describe a selected picture of a specific medical specialty in Italy. The findings can neither be generalised to other medical specialties nor to other countries.

\section{INTRODUCTION}

A core mission of medical societies is dissemination of scientific information. ${ }^{1}{ }^{2}$ They foster research in distinct fields of medicine, promote medical education and develop clinical guidelines. Authoritative medical associations are also influential in modulating practice, counselling administrators, advising politicians regarding public healthcare programmes and regulating professional conduct. Thus, the social role of these organisations entails exceedingly important clinical and ethical implications. ${ }^{1-4}$

However, some authors are concerned that economic aspects are interfering with the moral foundations of medical associations. ${ }^{1}$ In particular, a progressive imbalance has been observed in funding derived from membership dues and grants, and contracts awarded by government or charitable foundations, in favour of support from for-profit organisations. ${ }^{15-7}$ This situation may generate a conflict of interest (COI), which has been defined as 'a set of circumstances that 
creates a risk that professional judgment or actions regarding a primary interest will be unduly influenced by a secondary interest'. ${ }^{8}$ The primary interest of a scientific society is to promote the highest quality of care also through the education of its members. ${ }^{9}$ The secondary interest is, in this case, the financial well-being of the society together with the financial profit of some commercial entities. A COI may occur not only if a professional medical organisation (professional medical association, PMA) receives money from manufacturers of drugs or devices used in the same medical area of interest as the society, but also when individual officers of the organisation have personal financial ties to industries that could influence their actions and decisions within the PMA. Of note, COI is a condition, not a behaviour. In other words, when a COI exists, no actual unethical conduct has necessarily arisen. ${ }^{5}$ However, although COI and bias are not synonymous, the former is a demonstrated risk factor for the latter. ${ }^{10}$

Two different approaches have been suggested to deal with COIs of PMAs, that is, a divestment strategy (progressively discontinuing commercial support) and a management strategy (disclosing COIs and adopting rules to limit their potentially pernicious effects). ${ }^{59}$ As the operating budget of many PMAs is substantially based on industry funding, the latter policy has generally been preferred, purportedly to ensure stability in organisation functioning and to avoid curtailments in services to members. ${ }^{15-711}$ To be efficient, any strategy to 'manage' COIs about interactions with industry, should be based on thorough financial transparency, particularly, but not exclusively, regarding commercial support of annual meetings. In fact, most PMAs base their financial sustainability on revenues from periodic congresses, as in these occasions industry generally purchases exhibit hall space, sponsors conference sessions or satellite symposia, pays the registration fee for a variable number of attendees and buys advertising opportunities. ${ }^{291213}$

Further complicating the above scenario, the past decades have witnessed a tendency towards proliferation of medical societies focused on subspecialty areas or even single diseases, paralleling the general trend of modern medicine in the direction of overspecialisation. ${ }^{14}$ The intrinsic benefit of creating small and subspecialty associations is the possibility of increasing knowledge on specific disorders. However, compared with major national and international organisations, small societies may have less impact regarding public advocacy, information of healthcare decision makers and definition of public health system strategies. Moreover, small societies generally have restricted financial resources, thus their possibility to fund research seems limited. In this regard, the proliferation of subspecialty medical associations could also be viewed as a potential waste of precious resources that could be invested more efficiently in the interest of patients.

In addition, the quality of the information disseminated by scientific organisations should be scrutinised with care. Intellectual independence is essential, especially when providing continuing medical education (CME) activity, ${ }^{10}{ }^{15-17}$ but fragmentation and subspecialisation may expose medical societies to increased financial vulnerability and, hypothetically, this could result in an increase in the risk of undue influence of pharmaceutical, biotechnology and device industries. Noteworthy, the percentage of the overall national funding for CME activities provided by industry is particularly high in Italy, with reported figures varying from $60 \%{ }^{18}$ to almost $100 \%{ }^{19}$ of the total expenditure.

The phenomenon of proliferation of professional organisations appears to be particularly intense in the gynaecological field, probably owing to the multitude of issues regarding women's health. Therefore, we decided to conduct a survey in order to examine the condition of obstetrical and gynaecological societies in Italy. The primary objectives were to determine the overall number of associations and to verify whether a trend exists towards an increase in the number of subspecialty organisations over time. Secondary aims were to ascertain the societies' level of transparency regarding general competing interests and funding from industry, and to evaluate if a relation exists between the provision of CME activity and the degree of financial transparency.

\section{METHODS}

This survey was conducted by retrieving and analysing information from the internet. As publicly available data were used, the present study was exempt from the Ethics Committee's approval. The study was restricted to professional organisations active during 2014 in Italy. Websites were identified using 'Google', consistently ranked as the most popular search engine (http://www.google. com).$^{20}$ The following Italian search terms and phrases were used: 'Italian obstetrical and gynaecological societies', 'obstetrical and gynaecological societies AND Italy', ' Italian obstetrical and gynaecological associations', 'obstetrical and gynaecological associations AND Italy', 'Italian obstetrical and gynaecological federations', 'obstetrical and gynaecological federations AND Italy', 'Italian obstetrical and gynaecological organisations' and 'obstetrical and gynaecological organisations AND Italy'. In addition, the websites of the two major national obstetrical and gynaecological societies (Società Italiana di Ginecologia e Ostetricia, SIGO; Associazione Ostetrici Ginecologi Ospedalieri Italiani, AOGOI) were examined with the objective of identifying all the subspecialty organisations in the field affiliated to SIGO and AOGOI. All the authors independently conducted the initial search from 31 October to 7 November 2014. After completion of the list of associations, these were categorised, based on their name, into combined obstetrical and gynaecological, obstetrical only and gynaecological only organisations.

Individual societies' websites were then independently scrutinised from 8 November to 12 December 2014, and 
from 15 to 19 June 2015, by two authors (PVe and MPF), in order to verify the correctness of the initial categorisation, and to ascertain whether the association was public (ie, not privately owned by single individuals), and with a defined mission and a regular board, including a president, a treasurer, a secretary and an executive committee. Individual or privately owned organisations, those not specifically aimed at physicians and those with a religious or political profile, were excluded. Moreover, information was collected on standardised abstraction forms on 12 items defining two domains, those being, (1) the general characteristics of the society and its website (year of establishment; whether the headquarters were independent or located in the offices of a professional congress organiser and accredited CME provider; online availability of the society's bylaws; provision of CME activity; inclusion of sponsored sessions or symposia in the society's last annual meeting programme; presence on the society's website of industry advertisement or links to industries' websites) and (2) the financial transparency of the association (discussion of financial COIs in the society's bylaws; adoption of a policy for interactions with industry; availability of financial COI disclosures of the presidential trio (president, past president and president-elect), board members and executive staff; online availability of annual financial statement; disclosure of restricted and unrestricted industry grants and individual donations; and indication of industry sponsorship in the last annual meeting programme based on informative printed text in addition to mere logo inclusion).

In cases where the information on a PMA's year of establishment was missing, the executive staff members of the above two major national obstetrical and gynaecological societies were consulted by email and telephone. Moreover, PVe directly contacted the presidents and selected board members of some associations in order to obtain missing data from original documents. A final extraction form was compiled from the two separate evaluation forms, with correction or resolution of any discrepancies between abstractors by consensus reached after discussion or further joint re-examination of selected societies' websites.

In addition, two authors independently used the Health on the Net Foundation Code of Conduct ${ }^{21}$ for medical websites, with the objective of examining the degree of transparency of the healthcare information provided on the websites of the two major national obstetrical and gynaecological associations, SIGO and AOGOI. The HONcode is an instrument developed to assess the intent of a website to publish accurate information, and it includes items on transparency, financial disclosure and advertising policy. ${ }^{21}$

\section{RESULTS}

The initial web search yielded 56 professional obstetrical and gynaecological associations, but two were immediately excluded because they were known to be privately owned (Società Italiana Studi di Medicina della Riproduzione, SISMeR) or individually managed (Fondazione Graziottin per la Cura del Dolore nella Donna). Examination of societies' websites resulted in the exclusion of three organisations with defined sociopolitical or religious characteristics (Associazione Italiana Ginecologi Ostetrici Cattolici, AICOG; Società Italiana Procreazione Responsabile, SIPRe; Libera Associazione Italiana Ginecologi per l'Applicazione della Legge 194/78, LAIGA). One association (Confederazione Italiana Ginecologi Ospedalieri, CIGO) was excluded because its activities were unclear and not typical of a regular scientific society (eg, organisation of conferences and development of clinical recommendations). Another association was apparently no longer currently active (Società Italiana di Endoscopia e Laserterapia in Ginecologia, SIELG). Only one reviewer excluded two other organisations. Joint re-examination of the two websites demonstrated that the activity of one association (Fondazione Confalonieri Ragonese) was limited to drafting clinical practice recommendations on behalf of AOGOI, whereas the activity of the other (Associazione Italiana di Ostetricia, AIO) was aimed mainly at midwives rather than at physicians. A shared decision was taken to exclude the latter two organisations.

Summary characteristics of the remaining 47 professional associations are shown in table 1 . Individual societies' details regarding the general characteristics of the associations and their websites as well as PMAs' financial transparency are included in online supplementary table S1.

A total of 24 organisations were affiliated with SIGO (http://www.sigo.it/societa-affiliate/) and 6 with AOGOI (http://www.aogoi.it/opencms/sezioniOriz/

societaAffiliate/index.html). Seventeen 'generalist' associations covered both obstetrics and gynaecology (the 2 main ones plus 15 minor societies), 4 were specialised in obstetrical areas only and 26 were specialised in gynaecological areas only. In this latter group, seven organisations dealt with infertility, four with pelvic and endoscopic surgery, four with urogynaecology and two with, respectively, cervical pathology, and contraception and climacteric. After exclusion of the 17 'generalist' organisations, the distribution of societies' main area of interest was substantially skewed towards gynaecology $(26 / 30 ; 87 \%)$.

Six societies did not appear to have a website. In 12 cases, including those in which a website could not be found, the year of establishment of the association was obtained from SIGO or AOGOI executive personnel, and from direct contact between PVe and presidents or past-presidents. In the period 1980-2014, the number of Italian obstetrical and gynaecological societies has quadrupled, starting from 12 and increasing at a mean rate of one society per year over the last 35 years (figure 1 ). 
Table 1 General characteristics and financial transparency of Italian professional obstetrical and gynaecological associations extracted from their websites

\begin{tabular}{|c|c|c|c|c|c|c|c|c|c|c|c|c|}
\hline $\begin{array}{l}\text { Clinical and } \\
\text { research } \\
\text { area }\end{array}$ & $\begin{array}{l}\text { Number } \\
\text { with } \\
\text { website }\end{array}$ & $\begin{array}{l}\text { Headquarters } \\
\text { located in the } \\
\text { offices of a } \\
\text { professional } \\
\text { congress } \\
\text { organiser }\end{array}$ & $\begin{array}{l}\text { Society } \\
\text { bylaws } \\
\text { posted } \\
\text { on } \\
\text { website }\end{array}$ & $\begin{array}{l}\text { CME } \\
\text { activity* }\end{array}$ & $\begin{array}{l}\text { Sponsored } \\
\text { session/ } \\
\text { symposia } \\
\text { included in } \\
\text { the PMA's } \\
\text { last annual } \\
\text { meeting } \\
\text { programme }\end{array}$ & $\begin{array}{l}\text { Industry } \\
\text { advertisement } \\
\text { on society's } \\
\text { website or } \\
\text { links to } \\
\text { industries' } \\
\text { websites }\end{array}$ & $\begin{array}{l}\text { Financial } \\
\text { COI issue } \\
\text { discussed } \\
\text { in bylaws }\end{array}$ & $\begin{array}{l}\text { Policy for } \\
\text { interaction } \\
\text { with } \\
\text { industry } \\
\text { available } \\
\text { online† }\end{array}$ & $\begin{array}{l}\text { Financial } \\
\text { COls of } \\
\text { presidents, } \\
\text { board } \\
\text { members } \\
\text { and } \\
\text { executive } \\
\text { staff } \\
\text { disclosed } \\
\text { on website }\end{array}$ & $\begin{array}{l}\text { Annual } \\
\text { financial } \\
\text { statement } \\
\text { available } \\
\text { online }\end{array}$ & $\begin{array}{l}\text { Disclosure } \\
\text { of financial } \\
\text { support } \\
\text { (industry } \\
\text { grants and } \\
\text { individual } \\
\text { donations) } \\
\text { available } \\
\text { online }\end{array}$ & $\begin{array}{l}\text { Industry } \\
\text { sponsorship } \\
\text { indicated in } \\
\text { the PMA's } \\
\text { last annual } \\
\text { meeting } \\
\text { programme }\end{array}$ \\
\hline $\begin{array}{l}\text { Obstetrics } \\
\text { and } \\
\text { gynaecology } \\
(n=17)\end{array}$ & 14 & 7 & 12 & 17 & 4 & 8 & 0 & 0 & 0 & 0 & 0 & 8 \\
\hline $\begin{array}{l}\text { Obstetrics } \\
\text { only }(n=4)\end{array}$ & 4 & 1 & 2 & 4 & 0 & 0 & 0 & 0 & 0 & 0 & 0 & 0 \\
\hline $\begin{array}{l}\text { Gynaecology } \\
\text { only }(n=26)\end{array}$ & 23 & 7 & 18 & 25 & 5 & 4 & 0 & 0 & 0 & 1 & 0 & 7 \\
\hline
\end{tabular}


Figure 1 Variation in the number of Italian obstetrical and gynaecological societies over time. The number on top of each column is the number of societies.

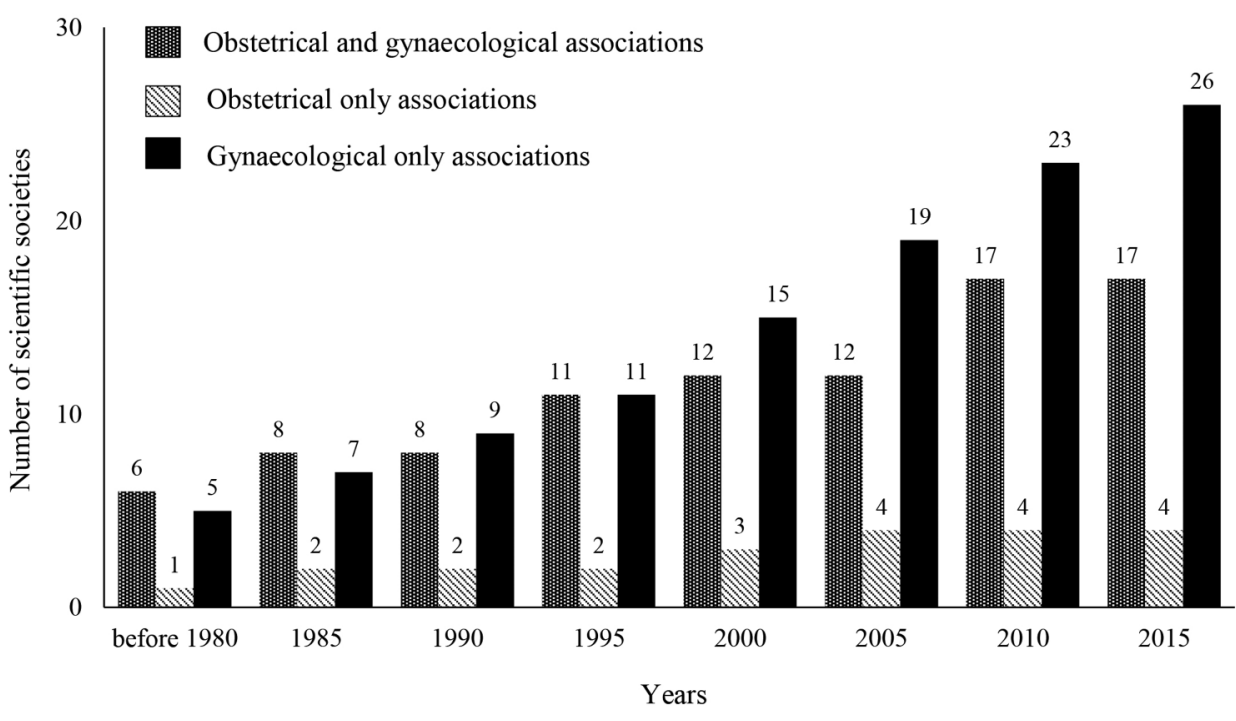

The headquarters of the associations were independent in 26/41 instances, and located in the offices of a professional congress organiser and accredited CME provider in the remaining 15 . Societies' bylaws were published online for $32 / 41(78 \%)$ of the identified websites. Forty-six associations organised conferences and provided CME activities. When an official society's website was not identified or when the information was not indicated on its website, CME activity was verified by scrutinising the online programmes of the society's conferences and courses. A total of 9/46 associations included sponsored sessions or symposia in their last annual meeting programme. Advertisements or links to industry products were present on 12/41 societies' websites ( 8 in the obstetrical and gynaecological subgroup and 4 in the gynaecological only subgroup).

With regard to financial transparency, in none of the 32 developed bylaws was the issue of COIs mentioned. No association had apparently developed a policy for interactions with industry. A total of 423 board members were identified, including the presidential trios, treasurers and secretaries. Forty-eight members were included at the same time on the board of two distinct organisations, 14 members on the board of three organisations and five on the board of four organisations. The competing interest disclosures of board members and executive staff were never posted on societies' websites.

The annual financial statement was published online in only one case and, with this exception, no information was publicly available on any other website regarding the society's source of financial support, as no data was accessible on restricted and unrestricted industry grants or individual donations, nor on industry sponsorship for the last annual meetings, courses or other educational events.

Evaluation of transparency of SIGO and AOGOI websites according to the HONcode principles ${ }^{21}$ identified lack of information (see online supplementary table S2). In particular, neither website attributed specific health/ medical information to an author; the sources of the funding for both sites were not clearly described; advertising was not always identified as such; and the sites were part of a link/banner exchange but there was no specific description about the site advertising policy. Moreover, the SIGO website did not provide the last modification date, and made claims relating to the benefit or performance of a specific medical treatment, commercial product or service based on the author's personal research or opinion.

Both websites provided free CME e-learning courses supported by pharmaceutical industries manufacturing drugs or commercial products used specifically in those medical areas on which the courses were focused. Finally, the SIGO website included descriptions of some campaigns supported by industries with direct or indirect interests in related medical fields.

\section{DISCUSSION}

The results of the present survey on Italian obstetrical and gynaecological societies and content analysis of their websites depict an academic scenario that warrants consideration. Remarkably large numbers of organisations were identified, characterised by a progressive and impressive increase over time, especially during the last decades. We do not have a clear explanation for this phenomenon. According to the list of member societies of the Federazione delle Società Medico-Scientifiche Italiane (Italian Federation of Medical-Scientific Societies, FISM), which includes Italian medical and scientific societies involved in medical education or research activities of national interest, this situation does not seem to be generalisable to other medical specialties. ${ }^{22}$ Of note, the gynaecological subgroup was characterised by several replications, particularly in the fertility and sterility, pelvic and endoscopic surgery, and urogynaecology areas. The reason for these duplications is not readily understandable. 
The observed disproportion in the distribution of subspecialty associations decidedly cannot be explained by unequal distribution of the clinical content of the two main areas of the addressed specialty-obstetrics and gynaecology. Thus, it could be hypothesised that Italian gynaecologists were more scientifically proactive compared with their obstetrical colleagues, but we could not find evidence to support this interpretation. An alternative theoretical explanation of this observation is that commercial sponsorship skewed the topics in favour of disorders from which a larger profit could be made. In this regard, gynaecology might prove a more lucrative medical area compared with obstetrics, at least in terms of markets for several costly new drugs, surgical devices and diagnostic tools. However, we have no data to support this hypothesis.

Financial transparency of the organisations included was almost non-existent, as we were unable to retrieve relevant, publicly available information, with the exception of the annual financial statement of a single, small gynaecological association. Six associations did not appear to have a website, thus providing no publicly available information. Unfortunately, online publishing of annual budgets and data regarding financial support is not a legal requirement for Italian scientific societies, and we could not identify alternative sources of information. We could not verify if and to what extent financial relations were in place between Italian obstetrical and gynaecological associations and industry, and we are unable to reject the hypothesis that they did not exist. This also applies to commercial support of annual meetings and educational events, although in this case, the obstetrical and gynaecological area would constitute an exception with respect to data on overall industry funding of Italian CME activities. ${ }^{18} 19$

We used websites as the main source of information regarding a society's financial transparency. It could be argued that websites can be useful to identify national PMAs, but they provide no accurate specific information on COIs and commercial funding. This constitutes a limitation of our study, as we could have sent a questionnaire directly to individual medical organisations or interviewed the president and executive officers. However, the aim of our survey was to verify whether information regarding COIs of board members and industry support of Italian gynaecological societies was easily and publicly accessible, which, nowadays, means posted on a society's website. ${ }^{17}$ The concept of transparency should not imply the need for individual investigation into a society's board members or executive staff by doctors and citizens to acquire this type of information.

Almost all the identified societies provided CME activity through conferences and courses. Lack of disclosure regarding industry support for scientific events involving CME activity (or lack of a website) in societies' websites is neither surprising nor unlawful, but raises ethical concerns. Some relevant information can be retrieved from the website of the Agenzia Nazionale per i Servizi Sanitari Regionali (Age.na.s), which manages the national CME programme on behalf of the Italian Ministry of Health. However, although the industries sponsoring the events are listed, the financial support is expressed as a relative percentage of an overall budget that is not quantified (http://ecm.agenas.it/BancaDati/ SB_Lista_Cerca_Accr.asp; accessed on 23 March 2015).

Independently of legal requirements, we believe that scientific societies should provide data on industry support of CME activity spontaneously, and should post it on their websites. This seems particularly important when the organisations delivering CME activity, which is a source of income for the provider, do not have independent headquarters, but are hosted by professional congress organisers who may receive money also from pharmaceutical companies and manufacturers of medical devices, ${ }^{23}{ }^{24}$ or when advertisements or links to industry products are included in their websites. However, without a formal evaluation of CME 'products' (ie, scientific quality and compliance with society mandate), no conclusions can be drawn.

Competing interests of members of the boards and executive committees of a society were also not disclosed, and this appears somewhat concerning. ${ }^{1}{ }^{5}{ }^{9}$ In general, finding experts without competing interests is difficult, and, ideally, they would all be concentrated in the boards of a few major obstetrical and gynaecological societies. The multiplication of boards and committees needed as a consequence of the proliferation of smaller organisations, particularly in the gynaecological area, implies that most of their directors and executives will have COIs, simply because there are not sufficient experts without COIs to cover all the available positions. This may have implications regarding a society's activities, including the development of practice guidelines. ${ }^{25}$ This issue would be greater if members with COIs serve on the board of more than one association.

Taking a selected picture of a specific country is a limit of our study that impedes generalisation of the findings. However, we considered that this survey allowed us to define a general scheme to be adopted for an investigation of this type, identifying reasonable end points and specific information categories. We are not aware of similar surveys published in the scientific literature, and believe that this scheme could also be used to investigate the condition of PMAs in different specialties and in different countries.

Rothman and coworkers described in detail the many potential threats to PMAs' integrity, identified specific COIs that may affect the organisations' activity, and formulated guidelines to prevent undue industry influence aimed at divestment from commercial support rather than management of financial competing interests. ${ }^{2}$ In fact, the authors maintain that "PMAs should work toward a complete ban on pharmaceutical and medical device industry funding $(\$ 0)$, except for income from journal advertising and exhibit hall fees." ${ }^{2}$ 
The Council of Medical Specialty Societies was created in the USA in 1965, with the objective of providing an independent forum for cross-specialty collaboration in order to influence policy on issues with a nationwide scope, such as medical education and accreditation. The Council has issued a code for interactions with companies that includes seven core principles covering COI, financial disclosure, independent programme development and independent leadership. ${ }^{26}$ With regard to transparency, the code states that 'Societies will make their conflict of interest policies and/or forms available to their members and the public', and 'Societies will disclose company support (at a minimum, educational grants, corporate sponsorships, charitable contributions and support of research grants), making this information available to their members and the public', and 'Societies will disclose all financial and uncompensated relationships that key society leaders and members of the board of directors of the society' membership organization have with companies, making this information available to their members and the public'. ${ }^{26}$ Up to now, the code has been signed by 32 North-American member societies of the Council and by 17 North-American non-member societies. ${ }^{27}$

Examples already exist of PMAs disclosing on their website the breakdown of industry contribution towards the consolidated revenue of the society, as well as disclosure statements reported by each member of the board of directors, ${ }^{28}$ and publishing-in meeting programmes - the company from which payment is received, the amount of payment by categories, and the specific type of relationship held with the company. ${ }^{29}$ A policy on rigorous control over COIs has been implemented by several medical and surgical scientific societies, ${ }^{19}{ }^{28-34}$ in some cases without detrimental consequences in terms of finances, membership, attendance at annual meetings or leadership recruitment. ${ }^{29} 3132$

It is currently unclear if the observed progressive growth in the number of gynaecological associations, together with the relative congresses and courses, does more good than harm to patients. ${ }^{35}$ Future research should aim at verifying whether this phenomenon results exclusively in enhanced knowledge and translates into better care of women's health, or if it facilitates the dissemination of partly biased information within the scientific community.

Italian scientists should lobby for transparency of public disclosure of COIs of societies providing CME activity and on implementation of efficient societies' policies for interactions with industry. Moreover, the Ministry of Health should only grant CME credits to conferences and educational events, provided that attendees are fully and publicly aware of financial connections between the scientific society and any industry involved, including quantitative information regarding funding for the meetings. ${ }^{36-38}$ More in general, a sort of Sunshine Act ${ }^{39}$ focused on scientific societies and educational activity, in addition to that aimed at individual doctors, and with potential application to multiple settings and jurisdictions, could prove of great benefit for patients, practising physicians and clinical investigators. A complete lack of transparency on the above issues nowadays appears hardly justifiable and ethically questionable. Indeed, COIs of PMAs might be considered more serious than those of individuals, because, where distorted information is disseminated at educational events, the effect would be multiplied with potential substantial consequences on prescribing practices of many of the society's members. ${ }^{3-5}$ Moreover, the definition of 'COI' itself, in the case of PMAs, may be somewhat misleading, as it has been pointed out that a medical organisation's commitment to patients and public health is a moral duty and not a mere interest. ${ }^{5}$

Collaboration between PMAs, and research and development departments of pharmacological companies and medical devices manufacturers, is very important for the advancement of medicine. This form of interaction is welcome in the interest of patients and society. On the contrary, collaboration between PMAs and company marketing departments on CME events and society annual meetings may blur the distinction between the interest of the PMA, which is education, and that of industry, which is selling products.

Despite individual or organisational COIs, the officers of many medical associations may well be disinterested and passionate, and provide valuable activities for the benefit of society members. However, members of PMAs are not the end users of drugs and devices marketed by industry; rather, they are the gatekeepers entrusted to make evidence-based recommendations to the real end user, that is, the patient. ${ }^{9}$ When the citizens eventually have to pay the bill, either directly or indirectly through national health systems, the conduct of PMAs may not be only based on the presumed good faith of their officers, but should contemplate the provision of publicly available and easily accessible data on financial competing interests. Transparency and disclosures do not eliminate COIs, ${ }^{40}{ }^{41}$ but may enable doctors and lay people to contextualise the scientific information disseminated in various ways by medical organisations, putting it in the right perspective.

Contributors PVe, PVi and ES conceived and planned the article. All the authors searched the web to identify Italian obstetrical and gynaecological societies. PVe and MPF scrutinised the societies' websites, retrieved and tabulated data. All the authors interpreted the data. PVe drafted the manuscript and all the authors revised it. All the authors approved the final version of the manuscript.

Funding This research received no specific grant from any funding agency in the public, commercial or not-for-profit sectors.

Competing interests PVe is the associate editor of Human Reproduction Update and past president of the World Endometriosis Society; PVi is the associate editor of Human Reproduction; ES is the deputy editor of Human Reproduction.

Provenance and peer review Not commissioned; externally peer reviewed.

Data sharing statement No additional data are available. 
Open Access This is an Open Access article distributed in accordance with the Creative Commons Attribution Non Commercial (CC BY-NC 4.0) license, which permits others to distribute, remix, adapt, build upon this work noncommercially, and license their derivative works on different terms, provided the original work is properly cited and the use is non-commercial. See: http:// creativecommons.org/licenses/by-nc/4.0/

\section{REFERENCES}

1. Pellegrino ED, Relman AS. Professional medical associations. Ethical and practical guidelines. JAMA 1999;282:984-5.

2. Rothman DJ, McDonald WJ, Berkowitz CD, et al. Professional medical associations and their relationships with industry: a proposal for controlling conflict of interest. JAMA 2009;301:1367-72.

3. Kassirer JP. Professional societies and industry support: what is the quid pro quo? Perspect Biol Med 2007;50:7-17.

4. Camilleri M, Parke DW II. Conflict of interest and professional organizations: considerations and recommendations. Acad Med 2010;85:85-91.

5. Brody $\mathrm{H}$. Professional medical organizations and commercial conflicts of interest: ethical issues. Ann Fam Med 2010;8:354-8.

6. Lenzer J. Many US medical associations and disease awareness groups depend heavily on funding by drug manufacturers. BMJ 2011;342:d2929.

7. Schatman ME. The medical-industrial complex and conflict of interest in pain education. Pain Med 2011;12:1710-2.

8. Institute of Medicine. Conflict of interest in medical research, education, and practice. Washington DC: The National Academies Press, 2009:46. http://books.nap.edu/openbook.php?record id=12598\&page =46 (accessed 15 Jun 2015).

9. Schofferman J. The medical-industrial complex, professional medical associations, and continuing medical education. Pain Med 2011;12:1713-9.

10. Lo $\mathrm{B}, \mathrm{Ott} \mathrm{C}$. What is the enemy in $\mathrm{CME}$, conflicts of interest or bias? JAMA 2013;310:1019-20.

11. Dalsing MC. Industry working with physicians through professional medical associations. J Vasc Surg 2011;54:41S-6S.

12. Isaacs D. Industry sponsorship of scientific meetings: peaks and troughs. J Paediatr Child Health 2012;48:547.

13. Spence D. End the scandal of free medical education. BMJ 2013;346:f3936.

14. Stitzenberg KB, Sheldon GF. Progressive specialization within general surgery: adding to the complexity of workforce planning. J Am Coll Surg 2005;201:925-32.

15. Steinbrook R. Commercial support and continuing medical education. N Engl J Med 2005;352:534-5.

16. Steinbrook R. Financial support of continuing medical education. JAMA 2008;299:1060-2.

17. Steinbrook R. Future directions in industry funding of continuing medical education. Arch Intern Med 2011;171:257-8.

18. Garattini L, Gritti S, De Compadri P, et al. Continuing Medical Education in six European countries: a comparative analysis. Health Policy 2010;94:246-54.

19. ESC Board. Relations between professional medical associations and the health-care industry, concerning scientific communication and continuing medical education: a Policy Statement from the European Society of Cardiology. Eur Heart J 2012;33:666-74.

20. Wikipedia. List of search engines by popularity. https://en.wikipedia. org/wiki/List_of_search_engines_by_popularity (accessed 26 Aug 2015)
21. Health on the Net Foundation. HONcode for web publisher. Site evaluation form. https://www.hon.ch/cgi-bin/HONcode/Inscription/ site_evaluation.pl?language=en\&userCategory=individuals (accessed 15 Jun 2015).

22. Federazione delle Società Medico-Scientifiche Italiane (FISM). The complete list of member societies. http://www.fism.it/soci/list.jhtml (accessed 26 Aug 2015)

23. Rothman SM, Brudney KF, Adair W, et al. Medical communication companies and industry grants. JAMA 2013;310:2554-8.

24. Schwartz LM, Woloshin S. Medical communication companies and continuing medical education: clouding the sunshine? JAMA 2013;310:2507-8.

25. Moynihan RN, Cooke GP, Doust JA, et al. Expanding disease definitions in guidelines and expert panel ties to industry: a cross-sectional study of common conditions in the United States. PLoS Med 2013;10:e1001500.

26. Council of Medical Specialty Societies. Code for interactions with companies. http://www.cmss.org/uploadedFiles/Site/ CMSS_Policies/CMSS Code for Interactions with Companies Approved Revised Version 3-19-11CLEAN.pdf (accessed 19 Jun 2015).

27. Council of Medical Specialty Societies. List of signers to the code for interactions with companies. http://www.cmss.org/OriginalSigners. aspx (accessed 19 Jun 2015).

28. Hutchins JC, Rydell CM, Griggs RC, et al. American Academy of Neurology policy on pharmaceutical and device industry support. Neurology 2012;78:750-4.

29. Schofferman JA, Eskay-Auerbach ML, Sawyer LS, et al. Conflict of interest and professional medical associations: the North American Spine Society experience. Spine J 2013;13:974-9.

30. Coyle SL, Ethics and Human Rights Committee, American College of Physicians-American Society of Internal Medicine.

Physician-industry relations. Part 2: organizational issues. Ann Intern Med 2002;136:403-6.

31. Schünemann HJ, Osborne M, Moss J, et al. An official American Thoracic Society Policy statement: managing conflict of interest in professional societies. Am J Respir Crit Care Med 2009;180: 564-80.

32. Minter RM, Angelos P, Coimbra R, et al. Ethical management of conflict of interest: proposed standards for academic surgical societies. J Am Coll Surg 2011;213:677-82.

33. ACG Professional Affairs Committee. The role of industry interactions with the American College of Gastroenterology. Am J Gastroenterol 2012;107:800-3.

34. American Society of Clinical Oncology. American Society of Clinical Oncology: policy for relationships with companies. J Clin Oncol 2013;31:2043-6.

35. Ioannidis JP. Are medical conferences useful? And for whom? JAMA 2012;307:1257-8.

36. Robertson J, Moynihan R, Walkom E, et al. Mandatory disclosures of pharmaceutical industry-funded events for health professionals. PLoS Med 2009;6:e1000128.

37. Vercellini $P$, Viganò $P$, Somigliana $E$. Who pays for this conference? It's time patients and doctors knew. BMJ 2014;348:g3748.

38. Vercellini $P$. If we want things to stay as they are, things will have to change. J R Soc Med 2014;107:386.

39. Silverman E. Everything you need to know about the Sunshine Act BMJ 2013;347:f4704.

40. Siwek J. AFP's conflict of interest policy: disclosure is not enough. Am Fam Physician 2014;89:161-7.

41. Wilson $M$. Is transparency really a panacea? J $R$ Soc Med 2014;107:216-17. 